\title{
ARTIGO ORIGINAL \\ Experiências de professores com o autismo: impacto no diagnóstico precoce e na inclusão escolar
}

\author{
Teachers' experiences with autism: impact on early diagnosis and school inclusion
}

Cirleine Costa Coutoㅁ, Maria Cândida de Carvalho Furtado², Adriana Zilly'ㄹ, Marta Angélica lossi Silva²

\section{RESUMO}

Objetivou-se compreender como a experiência com o autismo pode impactar na identificação de traços autísticos em alunos pelos professores da Educação Infantil, sob a perspectiva do diagnóstico precoce e da inclusão escolar. A abordagem metodológica foi de cunho qualitativo. Participaram do estudo dez professores de dez Centros Municipais de Educação Infantil de Foz do Iguaçu, Paraná, Brasil. Os dados foram coletados por meio de entrevistas semiestruturadas e analisados segundo análise de conteúdo, modalidade temática. Evidenciaram-se dois núcleos temáticos: "Conhecimentos, experiências e percepçôes sobre o Transtorno do Espectro do Autismo" e "O professor frente ao aluno com Transtorno do Espectro do Autismo e os investimentos para a detecçáo e inclusão". Concluiu-se que os professores são capazes de identificar sinais de autismo, contribuindo para o diagnóstico precoce e que experiências positivas cooperaram para a acurácia na detecção e para a inclusão escolar. Açóes intersetoriais e interprofissionais necessitam ser ampliadas a fim de oportunizar o acolhimento e o cuidado integral.

Descritores: Transtorno Autístico; Cuidado da Criança; Diagnóstico Precoce; Docentes; Inclusão Educacional.

\begin{abstract}
The objective was to understand how the experience with autism can impact on early childhood teachers' identification of autistic traits in students from the perspective of early diagnosis and school inclusion. The methodological approach was qualitative. Ten teachers from ten Municipal Centers of Early Childhood Education located in Foz do Iguaçu, Paraná, Brazil participated in the study. Data were collected through semi-structured interviews and analyzed according to content analysis, thematic modality. Two thematic nuclei emerged: "Knowledge, experiences and perceptions about Autism Spectrum Disorder" and "The teacher before the student with Autism Spectrum Disorder and investments for detection and inclusion". The conclusion was that teachers could identify signs of autism and contribute to early diagnosis, and positive experiences cooperated for accuracy in detection and school inclusion. Intersectoral and interprofessional actions should be expanded in order to provide the opportunity for user embracement and comprehensive care.
\end{abstract}

Descriptors: Autistic Disorder; Child Care; Early Diagnosis; Faculty; Mainstreaming (Education).

\footnotetext{
${ }^{1}$ Universidade Estadual do Oeste do Paraná — Foz do Iguaçu (PR), Brasil. E-mails: cirleine@yahoo.com.br; aazilly@hotmail.com

${ }^{2}$ Universidade de São Paulo — Ribeirão Preto (SP), Brasil. E-mails: mcandida@eerp.usp.br; maiossi@eerp.usp.br
}

Como citar este artigo: Couto CC, Furtado MCC, Zilly A, Silva MAI. Experiências de professores com o autismo: impacto no diagnóstico precoce e na inclusão escolar. Rev. Eletr. Enferm. [Internet]. 2019 [acesso em: ];21:55954. Disponível em: https://doi.org/10.5216/ree.v21.55954. 


\section{INTRODUÇÃO}

O Transtorno do Espectro do Autismo (TEA), ou autismo, é um transtorno do neurodesenvolvimento com etiologia multifatorial. Os critérios diagnósticos descritos no Manual Diagnóstico e Estatístico de Transtornos Mentais (DSM-5) ${ }^{(1)}$ são:

- prejuízos na comunicação e interação social, com possíveis atrasos na aquisição da linguagem;

- padróes ritualizados de comportamento e interesses restritos, incluindo: movimentos e linguagem estereotipados e repetitivos, apego às rotinas, restrição dos interesses e distúrbios sensoriais.

Há ampla variabilidade na expressão dos traços autísticos, envolvendo diferenças na expressão dos sinais e níveis de gravidade. $\mathrm{O}$ autismo pode estar associado ou náo a atrasos na aquisição da linguagem e a comprometimento intelectual. Estima-se que o transtorno esteja presente em um a cada 88 indivíduos, segundo dados internacionais ${ }^{(2)}$.

O TEA tem curso crônico e, em geral, traz incapacidade funcional, interferindo na autonomia para as atividades da vida diária ${ }^{(3)}$. Com o diagnóstico precoce, é possível estabelecer a terapêutica multiprofissional adequada desde a infância, modificando os aspectos críticos dos comprometimentos. Assim, aumenta as chances da pessoa ter uma independência relativa e maior inserção social ${ }^{(4)}$.

O diagnóstico precoce é o mais impactante fator modificador do curso do transtorno. Pesquisas têm sido conduzidas no sentido de elaborar ferramentas eficazes para que o TEA seja identificado nos primeiros anos de vida, permitindo uma intervenção terapêutica imediata ${ }^{(5)}$. Tal esforço justifica-se pela maior plasticidade das estruturas cerebrais da criança nos anos iniciais da vida, sendo um período mais sensível às intervençôes ${ }^{(6)}$.

Os professores são importantes agentes envolvidos na suspeita de autismo em crianças pequenas, após os familiares ${ }^{(7)}$. Pesquisadores na Espanha apontaram que a suspeita de autismo foi identificada em 79\% dos casos pela família e em 15\% dos casos pelos profissionais da educaçáo. Em 4\% dos casos o profissional relacionado foi o pediatra e em $2 \%$, o psicólogo ${ }^{(8)}$.

$\mathrm{O}$ olhar dos educadores, quanto à identificação dos sinais do TEA, pode ser considerado excelente aliado no diagnóstico precoce, uma vez que o contato com a mesma criança é contínuo e a observação mais detalhista ${ }^{(9,10)}$. Assim, a atenção sobre como estes profissionais compreendem e vivenciam o TEA assume relevância, inclusive em relação à inclusão escolar.

No Brasil, apesar dos educadores aparecerem no algoritmo do Ministério da Saúde para rastreamento de sinais autísticos $^{(6)}$, seu papel é pouco explorado. Evidencia-se este fato pela falta de descrição de fluxos efetivos entre as equipes da educação e da saúde.

Para a adequada inserção dos educadores nas redes de atenção, há a necessidade de compreender quais as dimensóes teóricas e práticas vivenciadas por eles em relação ao TEA, os pontos fortes e as necessidades. A apreensão desta realidade, com foco na qualificação das redes de atenção, é uma área carente de abordagens na literatura e possui significativa implicância prática, justificando esta investigação.

Este estudo, portanto, objetivou compreender como a experiência dos professores da Educação Infantil com o autismo pode impactar na identificação de traços autísticos em alunos e as repercussões na inclusão escolar, sob a ótica das redes de atenção à saúde. Pressupóe-se que o professor possa ser um importante agente de reconhecimento dos sinais precoces do autismo, além de ser peça fundamental para o êxito da inclusão escolar.

\section{MÉTODOS}

Pesquisa de abordagem qualitativa realizada com professores de Centros Municipais da Educação Infantil (CMEIs) de Foz do Iguaçu, Paraná, Brasil. Os 11 CMEIs eleitos como campo de estudo situam-se na região norte do município, área com maior número de escolas.

Os critérios de inclusão foram:

- professores com, no mínimo, três anos de atuação em sala de aula, o que viabilizou a seleção de participantes com experiência docente e de professores que passaram pela graduação após a implementação da obrigatoriedade da educação inclusiva na formação inicial;

- professores que ministravam aulas em níveis escolares além do berçário, permitindo contato direto com alunos pré-escolares.

Quando mais de um professor atendeu aos critérios de inclusão em cada CMEI, foi solicitado ao coordenador pedagógico de cada instituição que indicasse um professor dentre os elegíveis para a pesquisa, independentemente do nível de conhecimento ou experiência pessoal com o TEA. Selecionou-se, assim, um educador por escola, perfazendo um total de 10 participantes, considerando que uma das escolas não aceitou participar da pesquisa.

Os dados foram coletados entre os meses de setembro e dezembro de 2016, por meio de entrevistas semiestruturadas. Foram conduzidas a partir de um roteiro composto por dados de identificação dos participantes e por questóes abertas e norteadoras que versaram sobre o significado do autismo: a compreensão sobre crianças com TEA; a experiência do professor em lidar com alunos autistas; as potencialidades e dificuldades de pessoas com autismo na vida diária; e as opinióes sobre como ampliar a percepção dos professores em relação aos sinais suspeitos do autismo.

As entrevistas foram previamente agendadas em horário e local de escolha dos participantes, de modo que não interferisse nas atividades pedagógicas e garantindo 
sua privacidade. Tiveram duração média de 50 minutos, foram gravadas e posteriormente transcritas na íntegra pelo pesquisador principal.

A análise dos dados foi referenciada pela análise de conteúdo, modalidade temática ${ }^{(11)}$ :

- leitura compreensiva, visando impregnaçáo, visão de conjunto e apreensão das particularidades do material gerado pela pesquisa;

- classificaçáo dos depoimentos em categorias;

- identificação dos núcleos de sentidos;

- diálogo entre as ideias problematizadas e informaçóes de outros estudos; e

- síntese interpretativa, procurando articular objetivo do estudo, base teórico-conceitual adotada e dados empíricos.

A pesquisa foi analisada e aprovada pelo Comitê de Ética em Pesquisa da Universidade Estadual do Oeste do Paraná (UNIOESTE), sob o Parecer no 1.665.147. Aos participantes foi solicitado o consentimento, mediante a assinatura do Termo de Consentimento Livre e Esclarecido, conforme a Resolução no 466/2012 do Conselho Nacional de Saúde (CNS). A fim de garantir o anonimato dos participantes, estes foram identificados pela letra "P" para "Participante", seguida de algarismo arábico correspondente à cada entrevista, P.1, P.2 e assim, sucessivamente.

\section{RESULTADOS E DISCUSSÃO}

Os 10 participantes foram todos do sexo feminino, com idade média de 39 anos. A idade mínima foi de 24 anos e a máxima, de 53 anos. $\mathrm{O}$ tempo médio de experiência docente foi de 14,3 anos, sendo o tempo mínimo de cinco anos e o máximo de 27 anos.

Em relação à escolaridade, 100\% das professoras (10) possuíam nível superior completo. Com relação ao curso de especialização, 60\% das professoras (6) concluíram ou estavam cursando uma especialização e $40 \%$ (04) possuíam duas especializaçôes já finalizadas. Em relação às áreas de especialização, 60\% (6) especializaram-se na área da Educação Infantil, 10\% (1) em Educação Especial, 10\% (1) era pós-graduada em Educação Infantil e Pedagogia Escolar, 10\% (1) em Educação Infantil e Gestão Escolar e 10\% (1) em Educação Infantil e Educação com Ênfase na Inclusão (considerada aqui como especialização em Educação Especial). No total, 90\% (9) cursaram ou estavam cursando especialização em Educação Infantil e 20\% (2) na área da Educação Especial.

Somente 50\% (5) das professoras informaram ter algum tipo de experiência direta com indivíduos autistas. De modo geral, as participantes referiram que obtiveram conhecimentos teóricos sobre o TEA em cursos, treinamentos em serviço e informalmente em programas de televisão e internet.
Os resultados configuraram, a partir da análise compreensiva das falas dos sujeitos, a identificação de dois núcleos temáticos, a saber: "Conhecimentos, experiências e percepçóes sobre o Transtorno do Espectro do Autismo" e "O professor frente ao aluno com Transtorno do Espectro do Autismo e os investimentos para a detecção e inclusão”, os quais passaremos a discutir a seguir.

\section{Núcleo temático “conhecimentos, experiências e percepções sobre o transtorno do espectro do autismo"}

Em relação aos sinais característicos do TEA, os sujeitos, em sua maioria, destacaram a dificuldade na comunicação da criança como elemento importante no reconhecimento do autismo. A ausência do contato visual, o isolamento e a quietude excessiva da criança foram os pontos mais referenciados:

\section{[...] Se tá muito sentado, ou vai no parque e não brinca com os demais, fica sempre sozinho, sempre quietinho, ou fica [...] no mundo da lua, né? (P.3)}

A gente tem a noção de que é aquela criança, aquela pessoa que não se relaciona, que não conversa, que não olha nos olhos... [...] A gente tem a concepçâo que a socialização deles é mais difícil. (P.9)

A criança que senta ali e fica. Se esse aqui for o meu brinquedo, é só meu e é só com esse que eu brinco e sozinho. $O$ mundo em volta, não tem. (P.10)

No TEA, há comprometimento na comunicação verbal e não verbal, condiçáo ressaltada pelas participantes. A observação do prejuízo na comunicação não verbal é importante, porque outros transtornos que envolvem atrasos na linguagem expressiva podem ser confundidos com TEA ${ }^{(1)}$

Observou-se que a convivência das professoras com alunos autistas enriqueceu a compreensáo sobre aspectos mais sutis do comportamento social, como, por exemplo, a observação sobre como se processa o brincar no dia a dia. A observação do brincar é relevante no reconhecimento precoce do TEA, porque normalmente há prejuízo do jogo simbólico, do faz de conta ${ }^{(12)}$.

Em relaçáo às participantes que afirmaram possuir experiência direta com o TEA, o cotejo com outros distúrbios não autísticos, os diferentes níveis de gravidade e a ampla variação entre as manifestaçóes autistas foram constataçóes frequentes. Além disso, observou-se que o contato com mais alunos com autismo ampliou a possibilidade de comparação dos casos e trouxe maior qualidade na descrição dos comportamentos: 
[...] eu percebi muitos niveis da diferença de um autismo ao outro... e outras deficiências. [...] Eles também são diferentes entre eles, né? [...] eu achei que eles eram iguais [...] e não são... (P.1)

\section{[...] e o menino com Asperger é bem diferente do meu aluno} que eu tenho agora [...]. Não é bem assim como falam... (P.2)

Aspectos sobre a inflexibilidade frente às mudanças da rotina, alteraçóes no comportamento adaptativo e padróes ritualizados de condutas também emergiram mais das falas das participantes que tiveram a oportunidade de observar alunos com TEA:

[...] obsessão por alguma coisa redonda, por rodas... [...] ou se todos os dias ela vai chegar na minha sala e ela vai ter aquela mesma rotina. (P.1)

Caso eu vejo que ele não se adapta, dai eu passo pra direçẫo e tento chamar a mãe. (P.3)

A diferença entre crianças com desenvolvimento habitual e com TEA em relação à precaução pessoal em ambientes novos é observada pela P.2. Ela ressalta a presença dessa desinibição atípica em autistas:

Porque [...] esse aluno que eu percebi, assim, algo diferente, [no] primeiro dia de aula ele já entrou pela sala e já entrou assim, não com bagunça, [...] em nenhum momento ele estranhou [...]. (P.2)

Quando uma participante referiu convívio com apenas um aluno, a experiência, positiva, neutra ou traumática, assumiu-se como fio condutor para a percepçáo do TEA. A primeira e recente experiência em ter um aluno com TEA em sala de aula pode ser marcada por impacto traumático, em funçáo da falta de preparo do aluno para o ambiente escolar ${ }^{(13)}$. A P.3 chegou a contar com precisão os dias nos quais não foi agredida:

Antes de eu ter o meu aluno [...], eu não sabia como que era o autismo, né? [...] Tem dia que ele é um amor, mas tem dia que ele tá agressivo, que nem: ele me agride, eu apanho, apanho. Agora não; faz vinte e cinco dias que ele não me agride, então assim, são conquistas, né? [...] Trago pra mim, e é uma coisa que no começo do ano me prejudicou muito, assim, que mexeu com o meu emocional, e afetou na minha casa [...]. (P.3)

Vivências traumáticas relacionadas ao autismo no ambiente escolar proporcionaram uma visão mais sombria do transtorno, uma acentuação das dificuldades e uma distorção da sintomatologia autística. O comportamento disfuncional pode ser considerado uma das causas destas experiências frustrantes com alunos com TEA, gerando estresse, medo, sensação de impotência e baixa expectativa de eficácia como educador ${ }^{(13)}$.

Por outro lado, experiências positivas resultaram em uma melhor vinculaçáo afetiva e ampliaram a percepçáo das participantes sobre o TEA, habilitando-as a transpor o senso comum e as rotulaçóes.

De modo geral, as professoras conseguiram apontar os sinais principais do TEA, mesmo com lacunas no conhecimento técnico. A experiência permitiu a constatação das diferenças de manifestaçóes, contribuindo para o entendimento prático da variabilidade do espectro. Também trouxe maior profundidade na apreensão da sintomatologia.

Enfatiza-se que a oferta de capacitaçóes é fundamental para que os educadores ampliem o conhecimento sobre o funcionamento autístico, e assim contribuam para a detecção precoce, para o desenvolvimento global e formação dos alunos.

Assim, pressupóe-se que os educadores sejam capazes de rastrear alunos com traços autísticos nas escolas, condição também salientada em outras pesquisas ${ }^{(7,14)}$.

\section{Núcleo temático “o professor frente ao aluno com transtorno do espectro do autismo e os investimentos para a detecção e inclusão"}

A criança com TEA pode apresentar-se disfuncional no ambiente escolar. O investimento terapêutico é de grande valia para o processo de adaptação, proporcionando a ampliação do repertório de comportamentos ${ }^{(15-17)}$.

A terapêutica multidisciplinar permite que a criança execute açóes funcionais e compreenda solicitaçóes, algumas vezes através de modelos alternativos de comunicação ${ }^{(17-19)}$, envolvendo profissionais da Fonoaudiologia, Psicologia, Terapia Ocupacional, Psicopedagogia, dentre outras áreas ${ }^{(20)}$. A equipe multidisciplinar pode atuar como mediadora entre a saúde e a educaçáo no cenário das redes de atençáo, auxiliando na identificaçẫo dos sinais suspeitos de TEA ${ }^{(14)}$.

Reiteradamente a criança é "incluída" na sala de aula sem condiçóes de desenvolver seu potencial cognitivo e de socializaçáo. A rejeição de professores a ter alunos com TEA pode ser compreensível neste cenário, dificultando, posteriormente, tanto o reconhecimento de casos mais brandos em outros alunos, quanto o empenho na inclusão escolar ${ }^{(21)}$.

O papel do "professor-terapeuta" ganhou destaque nas falas das participantes que possuíam experiência direta com o TEA. O comportamento desadaptativo dos alunos autistas tornou imperativa a necessidade de priorizar açóes e rotinas que permitissem a convivência e o atendimento às necessidades básicas dos alunos. 
[...] porque quando ela chegou aqui, ela não fazia nada, sabe? Faz dois meses praticamente que ela tá aqui. Ela já senta, ela já pega os lápis, ela pinta, ela senta no chão pra brincar com os colegas, ela senta pra assistir. Então, a mãe dela diz que nada disso ela fazia nada disso. (P.5)

[...] eu tenho que largar a fila aqui, ir lá, pegar na mão, trazer e colocar ela em primeiro na fila, porque pra eu levar na fila, tenho que levar a mãozinha dela, caso contrário, se joga no chäo, chora, e fica ali. (P.10)

A sobrecarga do professor com atividades diversas gera experiências desagradáveis e compromete a inclusão escolar. O esforço despendido para ensinar a criança a sentar, comer, pegar o lápis, obedecer a ordens simples e a interagir, repertório de comportamentos trabalhado em ambientes terapêuticos com técnicas adequadas, deveria ter sido direcionado para o desenvolvimento pedagógico do aluno.

Essa também seria a expectativa do professor, ainda mais levando em consideração que o docente não foi preparado para abordar pessoas com TEA. A inclusão acaba se resumindo ao tratamento sem técnica no ambiente escolar e a uma inconveniente exclusão na escola:

[...] se ele inventa uma coisa, dai ele começa gritar, ele começa chorar, e [...] como é que você vai fazer isso sozinha? Daí você tem ele e tem mais uma turma de vinte, né? [...] você acaba dando atenção aos outros e você acaba... meio que deixando ele. E dai eu vejo que isso prejudica a criança. (P.2)

Esqueci a parte pedagógica [...], primeiro eu tenho que trabalhar [...] a socialização e a interação dele, ele tem que se sentir seguro nesse ambiente, né? (P.3)

Experiências nas quais houve evoluçáo da criança com autismo em sala de aula, mesmo tendo sido apenas de ordem comportamental, foram consideradas satisfatórias e produtivas, estimulando a busca pela inclusáo escolar. Houve o fortalecimento dos vínculos afetivos e a sensaçáo de dever cumprido por parte da educadora. Tal êxito refletiu-se na maneira de entender o TEA; o vislumbre das potencialidades e o delineamento das dificuldades foram explanados de maneira mais realista.

Os cursos, capacitaçóes e especializaçóes foram as requisiçôes mais frequentes das professoras no sentido de ampliar a atençáo para o diagnóstico precoce. Em especial, gostariam que estas qualificaçôes as ajudassem a lidar com crianças autistas em sala de aula. Algumas enfatizam a importância dos cursos sobre autismo serem custeados pela Secretaria de Educação ou Prefeitura Municipal, o que consideram um suporte mínimo para auxiliar na compreensão e inclusão escolar:
Eu acho que a gente tinha que ter mais capacitação, né? Mas isso tem que ser ofertado através da Secretaria; tem que ser dado curso, porque há alguns anos atrás a gente não ouvia falar do aluno com autismo em sala, mas agora vem aumentando o número de crianças. (P.2)

Então assim, pra eu lidar com essa situação do autismo, eu acho que teria que ter uma formação. [...] Um esclarecimento do que é autismo, de como trabalhar em sala [...]. (P.10)

A integraçáo entre educação e saúde, seja em relação ao diagnóstico, seja em relação ao seguimento dos casos, é a maneira ideal e menos dispendiosa de articular estratégias em Saúde Pública, especialmente na área pediátrica. A integração em rede destas instituiçóes sociais permite os ajustes necessários ao manejo de transtornos como o TEA desde muito cedo, evitando o ônus futuro da sustentaçáo de adultos dependentes totais ${ }^{(22)}$.

A intersetorialidade assegura melhores resultados no âmbito comunitário. Não se trata de abandonar ou corromper as especificidades das funçóes profissionais, mas de compartilhar responsabilidades de modo dinâmico, cultivando interfaces que dialogam entre as diferentes áreas ${ }^{(23)}$.

Portanto, é preciso pensar em açóes práticas de modo a integrar melhor o professor na rede de saúde e de assistência social, inserindo-o enquanto agente proativo permanente e com voz ativa, integrado a um fluxo funcional que permita o diálogo e o acolhimento das demandas. Da mesma maneira, o resultado das intervençôes em saúde, em uma perspectiva intersetorial e interprofissional, também necessita ter implementação efetiva e contínua na escola. Isso não implica na criação de novas estruturas e sim de promover a organização, a funcionalidade e a fluidez da conexão entre as diferentes áreas e saberes ${ }^{(24)}$.

Outra medida importante, neste contexto, envolve a necessidade de acesso das escolas aos serviços de saúde, nos quais existam profissionais aptos a realizar o diagnóstico do TEA. Esta articulaçáo possibilitaria encaminhamentos dos casos suspeitos pelos próprios professores a estes serviços táo logo as dificuldades das crianças fossem detectadas, evitando etapas intermediárias de encaminhamentos. Tal ação, respaldada em práticas de intersetorialidade funcionais de mão dupla, minimizaria atrasos diagnósticos e incluiria os professores como um dos agentes de detecçáo diagnóstica na Rede de Atenção Psicossocial (RAPS) voltada ao TEA ${ }^{(24)}$, teorizada pelo Ministério da Saúde brasileiro.

Iniciativas de matriciamento nas escolas, a partir do serviço de saúde especializado, assim como a discussáo conjunta de casos, permitiria a continuidade do cuidado integral às crianças com TEA ${ }^{(24,25)}$, além de oferecer suporte e assistência à equipe pedagógica, necessários ao adequado desenvolvimento infantil, à melhora da qualidade do convívio e do aprendizado. 


\section{CONCLUSÃO}

Os traços autísticos fundamentais foram apontados corretamente pelas participantes, independente da experiência com o tema, indicando, que professores são importantes agentes de apoio para o diagnóstico precoce. Isso demonstra que as escolas devem integrar a RAPS voltada ao TEA de modo mais expressivo, funcionando como ponto de apoio na triagem de sinais suspeitos.

Notou-se que a emergência de situaçóes vividas com alunos autistas em sala de aula afetou a qualidade das descriçóes da sintomatologia, assumindo maior profundidade quando as experiências foram positivas e diversificadas.

A percepção do TEA pelas professoras é fruto de uma teia intrincada de informaçóes adquiridas, sentimentos, vivências, ideias do senso comum, aspiraçóes e valores pessoais. Percebese que as opinióes sobre o autismo náo se resumiram apenas a informaçóes objetivas; vieram permeadas de elementos do cotidiano em sala de aula e das experiências pessoais, boas ou não, no contato com alunos com este transtorno.

A inserção do professor no fluxo do diagnóstico precoce do TEA e na inclusão escolar deve envolver suporte e apoio da equipe de saúde multidisciplinar na escola. Esta abordagem permite aumentar os índices de detecção de TEA em crianças pequenas e oportunizar o acolhimento, o cuidado integral e o estabelecimento de um clima salutar para todos na escola.

\section{REFERÊNCIAS}

1. American Psychiatric Association. Manual diagnóstico e estatístico de transtornos mentais: DSM-5. $5^{\mathrm{a}}$ ed. Porto Alegre: Artmed; 2014.

2. Gomes PTM, Lima LHL, Bueno MKG, Araújo LA, Souza NM. Autism in Brazil: a systematic review of family challenges and coping strategies. J Pediatr [Internet]. 2015 [acesso em: 8 ago. 2018];91(2):111-21. Disponível em: http://dx.doi.org/10.1016/j.jped.2014.08.009.

3. Hedley D, Uljarević M, Cameron L, Halder S, Richdale A, Dissanayake C. Employment programmes and interventions targeting adults with autism spectrum disorder: A systematic review of the literature. Autism [Internet]. 2017 [acesso em: 8 ago. 2018];21(8):929-41. Disponível em: https://doi. org/10.1177/1362361316661855.

4. Sanchack KE, Thomas CA. Autism Spectrum Disorder: primary care principles. Am Fam Physician [Internet]. 2016 [acesso em: 8 ago. 2018];94(12):972-80. Disponível em: https:/www.aafp.org/afp/2016/1215/p972.html.

5. Schwartzman JS, Velloso RL, D'Antino MEF, Santos $S$. The eye-tracking of social stimuli in patients with Rett Syndrome and autism spectrum disorders: a pilot study. Arq Neuro-Psiquiatr [Internet]. 2015 [acesso em: 8 ago. 2018];73(5):402-7. Disponível em: http:// dx.doi.org/10.1590/0004-282X20150033.

6. Ministério da Saúde. Diretrizes de Atenção à Reabilitação da Pessoa com transtornos do Espectro do Autismo (TEA) [Internet]. Brasília, DF: Ministério da Saúde; 2014 [acesso em: 6 ago. 2018]. Disponível em: http://bvsms.saude.gov.br/bvs/publicacoes/diretrizes atencao reabilitacao pessoa autismo.pdf.

7. Carvalho FA, Paula CS, Teixeira MCTV, Zaqueu LCC, D'Antino MEF. Rastreamento de sinais precoces de transtorno do espectro do autismo em crianças de creches de um município de São Paulo. Psicol Teor Prat [Internet]. 2013 [acesso em: 8 ago. 2018];15(2):144-54. Disponível em: http://pepsic. bvsalud.org/scielo.php?script=sci arttext\&pid=S1516$\underline{36872013000200011 \& \operatorname{lng}=\text { pt\&nrm=iso. }}$

8. Sevilla MSF, Bermúdez MOE, Sánchez JJC. Detección temprana del autismo: profesionales implicados. Rev Esp Salud Publica [Internet]. 2013 [acesso em: 8 ago 2018];87:191-9. Disponível em: http://dx.doi. org/10.4321/S1135-57272013000200008.

9. Prado $\mathrm{Al}$, Bressan RA. O estigma da mente: transformando o medo em conhecimento. Rev Psicopedag [Internet]. 2016 [acesso em: 8 ago. 2018];33(100):103-9. Disponível em: http://pepsic. bvsalud.org/scielo.php?script=sci arttext\&pid=S0103$84862016000100012 \& \operatorname{lng}=\mathrm{pt} \& \mathrm{nrm}=$ iso.

10. Andersson GW, Miniscalco C, Gillberg C. Preschoolers assessed for autism: Parent and teacher experiences of the diagnostic process. Res Dev Disabil [Internet]. 2014 [acesso em: 7 ago. 2018];35(12):3392-402. Disponível em: https://doi.org/10.1016/j.ridd.2014.08.027.

11. Bardin L. Análise de conteúdo. São Paulo: Edições 70; 2011.

12. Lin SK, Ching-Hong T, Hsing-Jung L, Chien-Yu H, Kuan-Lin C. Theory of mind predominantly associated with the quality, not quantity, of pretend play in children with autism spectrum disorder. Eur Child Adolesc Psychiatry [Internet]. 2017 [acesso em: 7 ago. 2018];26(10):1187-96. Disponível em: https://doi. org/10.1007/s00787-017-0973-3.

13. Sanini C, Bosa CA. Autismo e inclusão na educação infantil: crenças e autoeficácia da educadora. Estud Psicol (Natal) [Internet]. 2015 [acesso em: 21 jun. 2016];20(3):173-83. Disponível em: http://dx.doi. org/10.5935/1678-4669.20150019.

14. Zaqueu LCC, Teixeira MCTV, Alckmin-Carvalho F, Paula CS. Associaçóes entre sinais precoces de autismo, atençáo compartilhada e atrasos no desenvolvimento infantil. Psic: Teor e Pesq [Internet]. 2015 [acesso em: 8 ago. 2018];31(3):293-302. Disponível em: http:// dx.doi.org/10.1590/0102-37722015032243293302. 
15. Zalaquett DF, Schönstedt MG, Milagros A, Herrrera CC, Moyano AC. Fundamentos de la intervención temprana en niños con trastornos del espectro autista. Rev Chil Pediatr [Internet]. 2015 [acesso em: 8 ago. 2018];86(2):126-31. Disponível em: https://doi. org/10.1016/j.rchipe.2015.04.025.

16. Benevides TW, Carretta HJ, Shelly JL. Unmet need for therapy among children with Autism Spectrum Disorder: Results from the 2005-2006 and 2009-2010 National Survey of Children with Special Health Care Needs. Matern Child Health J [Internet]. 2016 [acesso em: 8 ago. 2018];20(4):87888. Disponível em: https://doi.org/10.1007/s10995015-1876-x.

17. Tiura M, Kim J, Detmers D, Baldi H. Predictors of longitudinal ABA treatment outcomes for children with autism: A growth curve analysis. Res Dev Disabil [Internet]. 2017 [acesso em: 6 ago. 2018];70:18597. Disponível em: https://doi.org/10.1016/j. ridd.2017.09.008.

18. Smith T, Iadarola S. Evidence base update for Autism Spectrum Disorder. J Clin Child Adolesc Psychol [Internet]. 2015 [acesso em: 6 ago. 2018];44(6):897922. Disponível em: https://doi.org/10.1080/1537441 6.2015.1077448.

19. Schreibman LE, Stahmer AC. A Randomized trial comparison of the effects of verbal and pictorial naturalistic communication strategies on spoken language for young children with autism. J Autism Dev Disord [Internet]. 2014 [acesso em: 8 ago. 2018];44(5):1244-51. Disponível em: https://doi.org/10.1007/s10803-013-1972-y.

20. Bhat S, Acharya UR, Adeli H, Bairy GM, Adeli A. Autism: cause factors, early diagnosis and therapies. Rev Neurosci [Internet]. 2014 [acesso em: 8 ago.
2018];25(6):841-50. Disponível em: https://doi. org/10.1515/revneuro-2014-0056.

21. Pimentel AGL, Fernandes FDM. A perspectiva de professores quanto ao trabalho com crianças com autismo. Audiol Commun Res [Internet]. 2014 [acesso em: 8 ago. 2018];19(2):171-8. Disponível em: http:// dx.doi.org/10.1590/S2317-64312014000200012.

22. Buescher AV, Cidav Z, Knapp M, Mandell DS. Costs of autism spectrum disorders in the United Kingdom and the United States. JAMA Pediatr [Internet]. 2014 [acesso em: 8 nov. 2018];168(8):721-8. Disponível em: https://jamanetwork.com/journals/jamapediatrics/ fullarticle/1879723. http://dx.doi.org/10.1001/ jamapediatrics.2014.210.

23. Lima RC, Couto MCV, Delgado PGG, Oliveira BDC. Indicadores sobre o cuidado a crianças e adolescentes com autismo na rede de CAPSi da regiáo metropolitana do Rio de Janeiro. Physis [Internet]. 2014 [acesso em: 8 nov. 2018];24(3):715-39. Disponível em: http:// dx.doi.org/10.1590/S0103-73312014000300004.

24. Ministério da Saúde, Secretaria de Atenção à Saúde, Departamento de Atenção Especializada e Temática. Linha de cuidado para a atenção às pessoas com transtornos do espectro do autismo e suas famílias na rede de atenção psicossocial do Sistema Único de Saúde [Internet]. Brasília, DF: Ministério da Saúde; 2015 [acesso em: 31 ago. 2018]. 156p. Disponível em: http:// bvsms.saude.gov.br/bvs/publicacoes/linha cuidado atencao pessoas transtorno.pdf.

25. Pinho LB, Kantorski LP, Saeki T, Duarte MLC, Sousa J. A integralidade no cuidado em saúde: um resgate de parte da produção científica da área. Rev Eletr Enf [Internet]. 2007 [acesso em: 8 ago. 2018];9(3):835-46. Disponível em: http://www.fen.ufg.br/revista/v9/n3/v9n3a22.htm. 